\title{
Richtlijn OSATS
}

\author{
E. Hiemstra en F.W. Jansen
}

\section{Voorwoord}

De Richtlijn OSATS is een deel-richtlijn en een bijzondere toepassing van de Richtlijn Korte praktijkbeoordeling (KPB). Het betreft een observatie van specifiek klinisch handelen, namelijk bij een operatieve ingreep, dat vastgelegd wordt op een scoringsformulier, gevolgd door feedback. Het verschil met de klassieke KPB is de duur van de observatie, die in de regel langer is dan bij een KPB, en de specifieke focus van de observatie.

De opdracht tot het ontwerpen van een In VIVO Richtlijn OSATS is verleend aan de In VIVO kernteams van Leiden en Amsterdam (AMC). De Richtlijn is geschreven door drs. Ellen Hiemstra (Haga Ziekenhuis, den Haag) en prof dr. Frank Jansen (LUMC).

\section{Status van de Richtlijn}

De Richtlijn beoogt een hulpmiddel te zijn bij de beoordeling van chirurgische procedures met OSATS en heeft geen dwingend karakter. OSATS is een beoordelingsinstrument voor snijdende vakken volgens het Kaderbesluit Centraal College Medische Specialismen (CCMS) 2011, maar behoort tot de groep van niet-verplichte instrumenten.

\section{Wat is een OSATS?}

OSATS is de afkorting voor: Objective Structured Assessment of Technical Skills. Het is ontwikkeld aan de universiteit van Toronto en werd daar (in studieverband) gebruikt om technische chirurgische vaardigheden van chirurgen in opleiding te objectiveren in skillslaboratoria. ${ }^{1}$ In het oorspronkelijke ontwerp bestaat een OSATS uit een taakspecifieke checklist, een geslaagd/gezakt oordeel en een algemeen beoordelingsformulier, bedoeld om toe te passen in een chirurgisch examen met gestandaardiseerde proefopstellingen. De commissie HOOG (Herstructurering Opleiding Obstetrie en Gynaecologie) heeft van deze procedure alleen het algemene beoordelingsformulier vertaald naar het Nederlands en opgenomen in haar ontwerpcurriculum voor de gemoderniseerde opleiding tot gynaecoloog. ${ }^{2}$ Dit onderdeel van de volledige OSATS wordt sindsdien in de Nederlandse context 'OSATS' genoemd. Het kan worden beschouwd als een korte praktijkbeoordeling van een chirurgische handeling, elders ook wel aangeduid met de term DOPS: Direct Observation of Procedural Skill. ${ }^{3}$ De OSATS kan worden gedefinieerd als 'een gerichte observatie van een chirurgische verrichting, geëvalueerd en vastgelegd op een standaardformulier'.

In de OSATS staan de onderstaande zeven technisch-chirurgische vaardigheden centraal:

1. Weefselgevoel

2. Tijd en beweging

3. Hanteren van instrumenten

4. Instrumentenkennis

5. Gebruik van assistentie

6. Voortgang operatie

7. Kennis van de procedure

Elk van deze aspecten van de chirurgische vaardigheid wordt beoordeeld op een formulier met een vijfpuntsschaal waarbij de punten 1, 3 en 5 in woorden zijn gedefi- 
nieerd. De complexiteit van de procedure of ingreep wordt op het formulier apart aangeduid met 'laag', 'gemiddeld' of 'hoog', zodat in de beoordeling daarmee rekening kan worden gehouden. Het standaardformulier voor de OSATS is als bijlage bij deze Richtlijn opgenomen.

\section{Doel van de OSATS}

Tegen de achtergrond van het competentiegerichte opleiden en de kritiek op uitsluitend numerieke eindtermen is er behoefte de chirurgische vaardigheid van de arts in opleiding tot specialist (aios) te objectiveren. Geen enkele beoordeling van vaardigheden is geheel vrij van subjectiviteit, maar een meer objectieve, gestandaardiseerde beoordeling is in de regel wel haalbaar. Naast de beoordeling van een enkele procedure kan een OSATS diverse doelen dienen: het kan een kapstok zijn voor het geven van gestructureerde feedback, de vooruitgang van de aios kan worden beoordeeld en zijn/haar individuele opleidingstraject kan op basis ervan zo nodig worden aangepast. Tot slot kan het beoordelen met OSATS een handvat zijn voor autorisatie c.q. bekwaamverklaring. ${ }^{4-5}$

\section{De kwaliteit van een beoordelings- systeem met OSATS}

Idealiter wordt de kwaliteit van een beoordelingsinstrument bepaald door het te vergelijken met de 'gouden standaard'. Voor het beoordelen van de chirurgische vaardigheden bestaat echter geen standaard. Een instrument dat die vaardigheden beoordeelt moet daarom voldoen aan drie algemene voorwaarden: de beoordeling moet uitvoerbaar zijn en het instrument moet valide en betrouwbaar zijn. ${ }^{6}$ Voor de OSATS zijn deze drie voorwaarden onderzocht. Het merendeel van dit kwaliteitsonderzoek vond plaats in skillslaboratoria. De validiteit werd aangetoond door te bewijzen dat het met hulp van OSATS mogelijk is te differentiëren in de vaardigheidsniveaus van experts en beginners. ${ }^{1}$ Gezien de verschillen in OSATS scores bleek dit instrument bovendien in staat om assistenten van een verschillend opleidingsjaar te onderscheiden. ${ }^{7}$ De betrouwbaarheid werd bewezen doordat de beoordelingen van verschillende beoordelaars in hoge mate overeen kwamen. ${ }^{1}$ Ook bleek het beoordelen van artsen in opleiding uitvoerbaar. ${ }^{8}$ Van bovenstaande onderzoeken dient vermeld te worden dat deze observaties alle in een skillslaboratorium plaatsvonden, en dus niet op echte operatieve handelingen zijn getest.

Er is beperkt onderzoek gedaan naar het gebruik tijdens chirurgische procedures op patiënten. Een recente studie vond een aanwijzing voor de validiteit van OSATS in de praktijk door aan te tonen dat chirurgen die meer dan honderd laparoscopische cholecystectomieën hadden verricht een hogere OSATS score behaalden op deze ingreep dan hun collega's die er minder dan tien hadden gedaan. ${ }^{9}$ Een implementatiestudie laat zien dat het gebruik van OSATS op de operatiekamers in het Leidse cluster voor specialisten in opleiding procedure-specifieke leercurven laat zien. ${ }^{10}$

\section{Wat en wie wordt met de OSATS beoordeeld en door wie?}

Artsen in opleiding tot chirurgisch specialist kunnen met een OSATS beoordeeld worden tijdens chirurgische ingrepen op de polikliniek of in de operatiekamer. De superviserende specialist is uit praktisch oogpunt de aangewezen beoordelaar. Daarnaast is het mogelijk dat een arts in de laatste fase van de specialistenopleiding een jongerejaars tijdens een operatie superviseert en beoordeelt met de OSATS. Het instrument is echter niet bedoeld voor de beoordeling van een operateur door andere leden van het operatieteam, 
zoals een instrumenterende of een anaesthesiemedewerker.

\section{Op welke wijze moet het OSATS formulier worden ingevuld?}

Het is belangrijk dat beoordelaars goed geïnstrueerd zijn hoe zij een OSATS moeten invullen om uniformiteit in beoordeling te realiseren. Eigenlijk is er maar één instructie nodig:

\section{'Omcirkel voor elk onderwerp het cijfer dat past bij de prestatie tijdens de ingreep, ongeacht het niveau van de beoordeelde.'}

Op dit punt verschilt de OSATS van de KPB waarbij vaak het verwachte niveau van de beoordeelde de norm is. Toch komt uit de implementatiestudie van OSATS op de operatiekamer naar voren dat er valkuilen bestaan bij het invullen: de scores die beoordelaars geven lopen sterk uiteen. ${ }^{10}$ De belangrijkste verklaring hiervoor is dat geen enkele beoordeling vrij van subjectiviteit is, ondanks het feit dat de OSATS in opzet een objectief instrument is.

\section{Met welke frequentie moeten OSATS worden toegepast?}

Er is in Nederland geen consensus over de frequentie waarmee de OSATS in de praktijk moet worden toegepast. Er is wel geopperd om elke ingreep waar een aios volledig of gedeeltelijk als eerste operateur functioneert, te beoordelen. Uit een enquête naar het gebruik van OSATS op de operatiekamer in het Leidse cluster (nog ongepubliceerd) kwam naar voren dat voor het merendeel van de beoordeelden met OSATS deze optie de voorkeur had. Toch is een selectie uit verrichte ingrepen voldoende om het niveau van een individu en de progressie in de tijd te kunnen bepalen. Een tweede optie is om voor aan- vang van het operatieprogramma een selectie uit de procedures van de dag te maken die beoordeeld zullen worden. Een derde mogelijkheid is dat aios en opleider na afloop van een procedure gezamenlijk beslissen of deze beoordeeld zal worden. Deze laatste optie verdient niet de voorkeur, omdat ze teveel een beroep doet op herinnering. Aangeraden wordt per afdeling of cluster een vaste systematiek in te voeren. Hierbij moet wel benadrukt worden dat het geven van feedback op chirurgisch handelen ook zonder de kapstok van de OSATS kan plaatsvinden.

\section{Wat gebeurt er met de beoordelingen?}

De OSATS is een goede kapstok voor directe constructieve feedback. Kenmerkend voor het gebruik van OSATS is dat de feedback op specifieke vaardigheden toegespitst kan worden.

OSATS kunnen voorts tijdens beoordelingsgesprekken gebruikt worden, enerzijds als serie van momenten ter onderbouwing van de evaluatie van de voorafgaande periode en anderzijds om leerdoelen te bepalen voor de naaste toekomst en eventueel het opleidingstraject aan te passen aan de individuele leerbehoefte.

Daarnaast kan OSATS tot hulp zijn bij de bekwaamverklaring voor een bepaalde ingreep (zie de Richtlijn over dit onderwerp). Enkelvoudige OSATS kunnen uiteraard deze functie niet hebben en de OSATS is ook niet ontworpen om een summatief totaaloordeel te vellen. Bekwaamverklaringen zijn zwaarwegende beslissingen en vereisen zeker dat een serie OSATS met een hoger dan gemiddelde score beschikbaar is, maar daarnaast spelen minder zichtbare kwaliteiten, c.q. andere competentiegebieden van CanMEDS, een rol bij de vraag of een operatieve ingreep zonder supervisie kan worden uitgevoerd. Kan er dan geen waardeoordeel op grond van een OSATS worden uitge- 
sproken? Uit de Leidse studie bleek dat een chirurgisch specialist in opleiding $90 \%$ van de maximale score moet behalen alvorens er geoordeeld wordt dat hij/zij in staat is de ingreep zelfstandig uit te voeren. Een indicatie om tot bekwaamverklaring over te gaan kan daarom zijn dat iemand drie opeenvolgende keren een OSATS score boven deze grens behaalt. Daarnaast moet de kans op, en de gevolgen van, eventuele complicaties per ingreep in de beslissing worden meegewogen.

Een voordeel van gebruik van OSATS is dat de zeven vaardigheden afzonderlijk kunnen worden beoordeeld. Deze afzonderlijke onderdelen kunnen ook verschillend worden gewaardeerd. Tot slot is het belangrijk dat opleiders en aios zich realiseren dat het proces van leren opereren ook na de bekwaamverklaring en zelfs na de opleiding doorgaat, ook al scoort iemand op alle onderwerpen maximaal.

\section{Kosten en opofferingen bij de toepassing van OSATS}

Het toepassen van OSATS zoals bedoeld in deze Richtlijn kost weinig moeite en inspanning, omdat, in tegenstelling tot de meeste vormen van KPB's en in tegenstelling tot de OSATS zoals die in Toronto is ontwikkeld en in een skillslab plaatsvindt, er weinig hoeft te worden georganiseerd om de observatie te laten plaatsvinden. Dat gebeurt met personen die toch al aanwezig zijn. Wat resteert is dat OSATS formulieren beschikbaar zijn als zij nodig zijn en dat stafleden goed geïnformeerd worden over de werkwijze en de normering bij de invulling. Voor de chirurgische opleidingen die met een digitaal portfoliosysteem werken is het OSATS formulier hierin opgenomen.

\section{Welke stappen zijn nodig voor de implementatie?}

Stap 1: Beslis per kliniek of per cluster wanneer een chirurgische procedure met een OSATS moet worden beoordeeld.

Stap 2: Informeer, instrueer en vooral motiveer arts-assistenten en opleiders over / voor beoordelingen met OSATS. Hierbij is de instructie voldoende dat de beoordelaar de operateur scoort overeenkomstig diens prestatie, ongeacht het verwachte niveau.

Stap 3: Zorg voor (toegang tot) beoordelingsformulieren voor alle aios. NB. Het initiatief voor de beoordeling ligt bij de aios; herinnering hieraan door de beoordelaar is gewenst.

Stap 4: Maak als opleiders en aios gebruik van de mogelijkheden die OSATS bieden.

\section{Evaluatie en bijstelling van de Richtlijn}

De implementatie van een beoordelingsinstrument als de OSATS mag niet zonder nadenken of evaluatie geschieden. Van belang is dat de OSATS slechts een onderdeel zijn van de beoordeling van het chirurgisch handelen. Voor het ontwikkelen van bekwaamheid in de chirurgie is meer nodig dan een hoge OSATS score. Implementatiestudies met kritische blik blijven ook in de toekomst nodig. Een geschikte termijn voor evaluatie is twee jaar na verschijnen van deze Richtlijn.

\section{Literatuur}

1. Martin JA, Regehr G, Reznick R, MacRae H, Murnaghan $\mathrm{J}$, Hutchison $\mathrm{C}$ et al. Objective structured assessment of technical skill (OSATS) for surgical residents. Br J Surg 1997;84(2):273-278.

2. http://www.medischevervolgopleidingen.nl//content/ documenten/specialisme/gynaecologie/nvog_ hoog.pdf

3. Norcini J, Burch V. Workplace-based assessment as an educational tool: AMEE Guide No. 31. Med Teach 2007;29(9):855-871.

4. Beard JD. Assessment of surgical competence. Br J Surg 2007;94(11):1315-1316. 
5. Darzi A, Smith S, Taffinder N. Assessing operative skill. Needs to become more objective. BMJ 1999; 318(7188):887-888.

6. Feldman LS, Sherman V, Fried GM. Using simulators to assess laparoscopic competence: ready for widespread use? Surgery 2004;135(1):28-42.

7. Swift SE, Carter JF. Institution and validation of an observed structured assessment of technical skills (OSATS) for obstetrics and gynecology residents and faculty. Am J Obstet Gynecol 2006; 195(2):617-621.

8. Goff B, Mandel L, Lentz G, Vanblaricom A, Oelschlager AM, Lee D et al. Assessment of resident surgical skills: is testing feasible? Am J Obstet Gynecol 2005;192(4):1331-1338.

9. Aggarwal R, Grantcharov T, Moorthy K, Milland T, Darzi A. Toward feasible, valid, and reliable video-based assessments of technical surgical skills in the operating room. Ann Surg 2008; 247(2):372-379.

10. Hiemstra E, Kolkman W, Wolterbeek R, Trimbos JBMZ, Jansen FW. The Value of an Objective Assessment Tool in the Operating Room. Accepted Can J Surg.
De auteurs:

Drs. E. Hiemstra is aios gynaecologie in het Leidse cluster.

Prof. dr. F.W. Jansen is gynaecoloog en hoogleraar Klinische Evaluatie van Minimaal Invasieve Chirurgische Instrumenten aan de Universiteit Leiden en de Technische Universiteit Delft.

\section{Correspondentieadres:}

Ellen Hiemstra, Leiden Universitair Medisch Centrum, afdeling Gynaecologie, K6-76, postbus 9600, 2300 RC Leiden.E-mail: E.Hiemstra@lumc.nl

Belangenconflict: geen vermeld

Financiële ondersteuning: geen vermeld 